\section{- Medicare Part D Coverage Gap Discount Program Beginning in 2011}

On May 12, 2010, the AMCP Executive Director sent a letter to Cynthia Tudor, Director, Medicare Drug Benefit and CED Data Group and Tom Hutchison, Director, Medicare Plan Payment Group, Centers for Medicare $\&$ Medicaid Services (CMS) regarding the draft guidance dated April 30, 2010, for implementation of the Medicare Coverage Gap Discount Program (the Discount Program), recently enacted as Section 3301 of the Patient Protection and Affordable Care Act (PPACA). ${ }^{1}$ Section 1860D-14A(d)(5) authorizes CMS to implement the Discount Program through program instruction. Following is the text of that letter:

Effective January 1, 2011, the Discount Program will make manufacturer discounts available to eligible Medicare beneficiaries receiving applicable covered Part D drugs while in the coverage gap. CMS has stated that discounts can only be provided at point-of-service (POS), as required by PPACA, if the entity adjudicating the electronic pharmacy claim has 4 pieces of necessary data:

- The drug is a discountable drug;

- The beneficiary is eligible for the discount;

- The claim is wholly or partially in the coverage gap; and

- The amount of the discount, taking into consideration plan supplemental benefits that pay first.

Because a Part D plan sponsor is the only entity with all 4 pieces of information, AMCP supports the proposed CMS plan for administration in general. However, the Academy does have comments on some of the specific provisions proposed by CMS. These comments refer to:

- CMS' statement in the draft guidance that the Discount Program does not affect how drug costs are projected;

- Questions focusing on year-end reconciliation and responsibility for collecting unpaid funds;

- Concerns related to specific provisions on securing manufacturer discount arrangements, transmitting updated listings of labeler codes covered by discounts, and communicating information to beneficiaries and pharmacies.

\section{CMS' Statement in the Draft Guidance That the Discount Program Does Not Affect How Drug Costs are Projected}

The Academy disagrees with the statement made in the draft guidance that the Discount Program does not affect how drug costs are reported and projected in Part D bids. AMCP believes the Discount Program will increase projections included in Part D bids. The coverage gap has served as a reminder of the cost of brand-name medications and, in spite of the negative implications of the coverage gap, it has encouraged beneficiaries to transition from brand-name medications to generic medications. Beneficiaries who make the transition to generic medications upon reaching the coverage gap continue on those medications after progressing into catastrophic coverage and then into the next coverage year. The Discount Program will reduce the incentive to use generics and will increase the rate that beneficiaries progress through the coverage gap, increasing the cost of the Part D prescription drug benefit. Although this does not impact the process that CMS creates to implement the Discount Program, the Academy asks that CMS correct such language.

The Academy does support CMS' acknowledgement that Part $\mathrm{D}$ sponsors will need to increase their administrative expense component of Part D bids. Part D plan sponsors will need to dedicate additional staff time to administering the Discount Program in order to address the system changes necessary to calculate Discount Program calculations and to process and account for the payments received both from CMS and from pharmaceutical manufacturers. Both administration of this complicated program as well as the lag time on payments from pharmaceutical manufacturers will contribute to a significant increase in administrative costs taken on by plan sponsors.

\section{Questions Focusing on Year-End Reconciliation and Responsibility for Collecting Unpaid Funds}

The Academy does have 2 questions concerning the process that CMS has proposed for Part D sponsors to recoup the discounts provided at point-of-service to beneficiaries. We understand the process will work in this manner:

Each month CMS will determine the prospective Discount Program payment; Part D plan sponsors will receive the prospective discount payments from CMS on the first of each month with their other Part D prospective payments. At the end of the contract year, CMS will reconcile the prospective Discount Program payments to cost based on the actual manufacturer discount amounts made available to each Part D plan's enrollees under the Discount Program. The actual discount amounts reimbursed by pharmaceutical manufacturers will be determined based on the manufacturer discount amounts reported by Part D sponsors in their prescription drug event (PDE) record submissions. A CMS contractor will invoice each manufacturer quarterly on behalf of Part D plan sponsors. Manufacturers will be required to pay the entire invoiced amount to Part D sponsors directly within 15 days of receipt including any amounts in dispute.

Our questions focus on the year-end reconciliation of any differential between the estimated amount of discounts paid to Part D plan sponsors and the actual total amount of discounts paid to beneficiaries.

1. What is the process that will be used to address the differential? If the Part D plan sponsor owes CMS a refund for the prospective discount payment, how and within what time frame will the payment be required?

2. Who bears the responsibility for collecting any unpaid funds from manufacturers - the contractor, the Part D plan sponsor, or CMS? 
Concerns Related to Specific Provisions on Securing Manufacturer Discount Arrangements, Transmitting Updated Listings of Labeler Codes Covered by Discounts, and Communicating Information to Beneficiaries and Pharmacies

The Academy has concerns with specific provisions of the system that CMS proposes to establish and communicate which medications are eligible for manufacturer-provided discounts:

- First, AMCP is concerned about the challenge that CMS will face in securing a manufacturer discount agreement with all pharmaceutical manufacturers to secure discounts for all brand medications. The Department of Defense (DOD) recently completed a similar process required under Section 703 of the National Defense Authorization Act for Fiscal Year 2008 (NDAA-2008). The regulation established a framework for manufacturers to pay refunds to the government on brand-name drugs dispensed to TRICARE beneficiaries under the TRICARE Retail Pharmacy Program. There are hundreds of pharmaceutical manufacturers that each produce only a few brand-name medications. Based on observing the DOD process, the Academy believes that it is highly unlikely that CMS will secure manufacturer discounts with all pharmaceutical manufacturers by the end of 2010. CMS has acknowledged that it will need to allow coverage in 2011 of some Part D drugs irrespective of manufacturer discount agreements and has indicated that it will provide clear public guidance on why discounts are not available for some formulary brand name drugs.

- The Academy is concerned about the process CMS has proposed to communicate necessary information on which drugs are covered by manufacturer discount agreements. According to the draft guidance, CMS will maintain an updated list of the labeler codes that are covered by the manufacturer discount agreements, distribute the list to Part D sponsors, and post the list on the CMS website. If plan sponsors are responsible to monitor the list for any changes, the system resembles the current nonmatched national drug code (NDC) list which has placed an unreasonable burden upon Part D sponsors. It has required extensive staff time to continually monitor the CMS nonmatched NDC list and the U.S. Food and Drug Administration database to keep Part D plan databases accurate. If CMS expects Part D sponsors to be responsible for administering the manufacturer discounts at point-of-sale, the CMS must actively notify plan sponsors when a drug has been added to the list of the labeler codes covered by the manufacturer discount agreement.

- The Academy encourages CMS to communicate information about nondiscounted brand name medications clearly to beneficiaries and retail pharmacies. It should not be the responsibility of Part D sponsors to share such information. CMS indicates that beginning in 2012, Part D sponsors must provide "prospective" notice to affected Part D enrollees if a covered Part D drug will no longer be covered for failure of a manufacturer to sign a manufacturer discount arrangement. CMS should allow plan sponsors to communicate all formulary changes made at the beginning of the plan year using one process whether the formulary change is due to the failure of a manufacturer to sign a discount arrangement or for some other plan-initiated reason.

The Academy realizes that the design of the pharmaceutical manufacturer Discount Program was set forth in the PPACA and that CMS would not have designed a program that would be this challenging to administer. However, the Academy asks that CMS address parts of the draft guidance that are unclear as to CMS' intent and make the program as viable as possible for Part D plan sponsors to administer by incorporating suggestions put forth in this letter.

\section{Judith A. Cahill \\ AMCP Executive Director \\ jcahill@amcp.org.}

\section{DISCLOSURES}

The author reports no conflicts of interest regarding the subject of this letter. AMCP is the publisher of JMCP, and AMCP represents the interests of pharmacists who practice in a broad range of managed care organizations including Medicare Part D sponsors.

\section{REFERENCES}

1. Centers for Medicare \& Medicaid Services. Center for Medicare. All Part D sponsors: Medicare coverage gap discount program beginning in 2011. April 30, 2010. Available at: http://www.cms.gov/PrescriptionDrugCovContra/Do wnloads/2011CoverageGapDiscount_043010.pdf. Accessed May 12, 2010. 